\title{
O MST e a Reforma Agrária do Consenso
}

\author{
Arlete Ramos dos SANTOS
}

\begin{abstract}
RESUMO: Este texto traz os resultados de uma pesquisa realizada na regional Extremo Sul da Bahia, que analisou a relação de parceria, os acordos e o diálogo estabelecido entre os movimentos sociais do campo, principalmente o Movimento Sem Terra (MST), o Estado e as empresas do agronegócio. Utilizamos a metodologia qualitativa de natureza exploratória, e os instrumentos de coleta de dados foram análise de documentos e entrevistas semiestruturadas. Os resultados apontaram que na região brasileira pesquisada está evidenciado um novo formato de reforma agrária, o qual estamos denominando de Reforma Agrária do Consenso.
\end{abstract}

PALAVRAS-CHAVE: Agronegócio. Ideologia. Movimentos sociais do campo. Reforma Agrária do Consenso.

\section{Introdução}

Este artigo aborda o resultado de uma pesquisa ${ }^{1}$ realizada na Regional Extremo Sul da Bahia que teve como objetivo principal analisar as contradições originadas em uma parceria entre os movimentos sociais do campo ${ }^{2}$, de cunho progressista, o governo do Estado da Bahia, de caráter (Neo)desenvolvimentista, e as empresas do agronegócio de eucalipto Fíbria S.A. e Veracel Celulose S.A.

\footnotetext{
UESC - Universidade Estadual de Santa Cruz. Ilhéus - BA - Brasil. 45662-900 - arlerp@hotmail.com. 1 Pesquisa de Pós-doutorado realizada na FCLAR/UNESP, Campus Araraquara-SP, sob a supervisão da Dra. Maria Orlanda Pinassi, cujo objeto de estudo trata das alianças estabelecidas entre os movimentos sociais do campo, o Estado e o agronegócio, na regional Extremo Sul da Bahia. Contou com financiamento da Fundação de Amparo à Pesquisa da Bahia - FAPESB e da UESC.

2 Movimento dos Trabalhadores Rurais Sem Terra (MST); Federação dos Trabalhadores na Agricultura (FETAG); Movimento de Luta pela Terra (MLT); Associação de Produtores Rurais Unidos Venceremos (PRUNVE); Movimento de Resistência Camponesa (MRC) e a Frente de Trabalhadores Livres (FTL).
} 
No contexto geral da pesquisa, buscamos compreender a relação antagônica entre reforma agrária, agronegócio e os movimentos sociais do campo. Entretanto, nesse texto não teremos espaço para discutir todos os resultados da pesquisa, por isso, optamos por recortar apenas os aspectos político-ideológicos que motivaram a realização da referida parceria, destacando, principalmente, o Movimento dos Trabalhadores Rurais Sem Terra (MST), na Bahia.

Observamos nessa relação dois aspectos antagônicos que discutiremos no texto, os quais estão diretamente relacionados à manutenção do conservadorismo capitalista naquela região onde a pesquisa aconteceu. $\mathrm{O}$ primeiro diz respeito a um consenso dos movimentos sociais com os interesses do agronegócio e do Estado na regional Extremo Sul da Bahia; o segundo está relacionado ao interesse do agronegócio em dispor recursos para implantação de projetos agroecológicos e de formação da militância camponesa, pautados na agricultura familiar, sendo que contraditoriamente, o agronegócio expandiu-se no contexto de 1970, como expoente da monocultura no Brasil, sendo exatamente este um dos motivos pelos quais têm acontecido os conflitos no campo entre o capitalismo agrário e o campesinato brasileiro.

Realizamos uma pesquisa qualitativa de natureza exploratória e os dados foram coletados por meio de análise documental e entrevistas semiestruturadas (GIL, 2002) com os dirigentes dos movimentos sociais pesquisados; o secretário e o assessor da Secretaria de Relações Institucionais do governo da Bahia (SERIN) e um gerente de sustentabilidade da empresa Veracel S.A. Outros sujeitos como a Fíbria S.A. e a Escola Superior de Agronomia da Universidade de São Paulo (ESALQ/ USP) que, inicialmente, foram elencadas como sujeitos, ao serem contatadas no momento da coleta de dados, nos informaram que só poderiam participar da pesquisa com a prévia autorização do MST.

Para análise do material coletado utilizamos a metodologia dialética visto que "a dialética é o pensamento crítico que se propõe a compreender a "coisa em si" e sistematicamente se pergunta como é possível chegar à compreensão da realidade" (KOSIK, 1997, p. 20). Em termos gerais, o materialismo histórico dialético é um enfoque teórico que contribui para desvelar a realidade, pois busca apreendêla a partir de suas contradições e relações entre singularidade, particularidade e universalidade. Em outras palavras, esse enfoque tende a analisar o real no seu desenvolvimento histórico, -sua gênese e desenvolvimento-, captando as categorias mediadoras que possibilitam a sua apreensão numa totalidade. Desta forma, nos apropriaremos da teorização, frente à realidade posta para compreendê-la, sempre confrontando e analisando aspectos empíricos, históricos, ideológicos, sociais, entre outros, em busca de interpretar o objeto de estudo em sua totalidade. 


\section{Lutas camponesas, reforma agrária e agronegócio: um debate ideológico}

Optamos por analisar as lutas camponesas associadas à reforma agrária e à sua relação com o agronegócio. De acordo com Thomaz Jr. (2008), a luta camponesa tem atingido várias regiões do mundo. Na Indonésia, acontece por meio de enfrentamentos entre camponeses e forças de segurança. Na Europa, por meio da aliança entre os verdes, ecologistas, movimentos camponeses, participação da Via Campesina, Organizações Não Governamentais (ONGs) contra os transgênicos nas lutas pró-soberania alimentar dos povos; pelos direitos das mulheres campesinas ao trabalho e à terra e pelas iniciativas dos assalariados rurais na Andaluzia; pelas experiências dos sindicatos dos Obreros Del Campo (SOC); dentre outros.

No contexto da América Latina, a reestruturação produtiva no campo atingiu os trabalhadores e movimentos sociais campesinos e resultou em formas de lutas que têm contribuído para redimensionar o debate teórico, político e social, por meio dos sindicatos, associações e partidos políticos, bem como, por meio da conquista de espaços desses sujeitos em vários países, como o Pachakutik, no Equador, os Zapatistas, no México, os indígenas, na Bolívia, os Sem Terra, no Brasil. As inovações nas formas de lutas têm sido uma característica fundante dessas mobilizações coletivas latino-americanas que enfrentam as estratégias utilizadas pelo capitalismo mundial na agricultura, a qual visa a espoliação dos camponeses, cujos fundamentos estão pautados nas políticas estruturais do Banco Mundial, do Fundo Monetário Internacional (FMI) e do regimento do livre comércio da Organização Mundial do Comércio (OMC) (THOMAZ JR., 2008).

As contradições daí originadas resultam em formas de resistências que motivam cada vez mais as lutas dos movimentos sociais camponeses e acirram a correlação de forças entre trabalhadores e detentores dos meios de produção no campo. Cabe esclarecer que a luta pela terra é diferente da luta pela Reforma Agrária. Enquanto a primeira acontece no Brasil desde a conquista do território brasileiro pelos portugueses, principalmente com as lutas indígenas, a segunda data da primeira metade do século XX, quando, no período compreendido entre 1948 e 1954, os camponeses brasileiros começam a articular a sua práxis com a luta contra o latifúndio, ainda sem ligações específicas com o proletariado das cidades. Porém, essa luta se concretizou com o Estatuto da Terra (Lei $n^{\circ}$ 4504/64), da gestão Castelo Branco e ainda se encontra em vigor por meio do Art. 186 da Constituição Federal, de 1988.

Observamos que no século XX, o mercado fundiário no Brasil garantiu que bens imobiliários rurais "fossem utilizados como reserva de valor e/ou fonte de 
lucros, por meio da apropriação parasitária de renda decorrente de incrementos do preço da terra. Daí que a simples propriedade da terra tenha permanecido substrato fundamental de riqueza em meio ao progresso técnico no campo brasileiro" (FARIAS, 2013, p. 34). Essa configuração fundiária aliada às políticas governamentais criou uma relação de concomitância entre a agricultura e a indústria, o que gerou a cultura do processamento agroindustrial, que contribuiu para a ampliação do grande capital no campo brasileiro, cujo propósito era a produção de commoditties. No Brasil, a concentração da propriedade da terra tem o predomínio da agroindústria, que por meio do agronegócio incorpora os setores agrícola, mercantil, industrial, ideológico, financeiro, tecnológico e educacional ${ }^{3}$. Não obstante, através do senso comum não crítico, o agronegócio tem procurado subordinar o campesinato e a agricultura familiar aos ditames do capitalismo mundial, submetendo-os às determinações dos organismos multilaterais por meio da submissão destes adquirida mediante a crença ilusória de independência aparente.

Abramovay (2007) toma como referência a realidade de países desenvolvidos para contextualizar a relação entre o agronegócio e o campesinato, justificando que o desenvolvimento do capitalismo pode proporcionar o fim do sujeito campesino porque, num determinado estágio da produção, a conjuntura socioeconômica cria relações de mercado entre ambos, extermina o modo de produção do camponês e o metamorfoseia transformando-o no profissional agricultor familiar, totalmente inserido no mercado e desprovido de consciência de classe camponesa. Esse paradigma é denominado de Paradigma do Capitalismo Agrário (PCA) por Abramovay (2007). A agricultura familiar (controle da família sobre os meios de produção, sendo ela a principal responsável pela efetivação do trabalho) perde, gradativamente, espaço para as grandes produções em escala das transnacionais, e estas, utilizando-se em parte de novos métodos de aumento da produção, principalmente, da biogenética, subjuga os agricultores familiares, tornando-os sua mão de obra, ou expulsando-os do campo.

Entretanto, apesar de Abramovay (2007) utilizar a organização do sistema capitalista agrário de maneira universal para decretar o fim do campesinato, isso não se concretizou efetivamente no Brasil, tendo em vista que diversos movimentos sociais camponeses ainda continuam suas lutas pela posse da terra no país atualmente, se organizando de forma coletiva, com uma práxis voltada para o enfrentamento ao capital, mediada pelas estratégias de luta cotidianas. Nesse caso, se destacam os movimentos sociais de trabalhadores camponeses organizados pela Via Campesina, os quais são responsáveis por diversos conflitos para conseguirem

\footnotetext{
3 As cartilhas do agronegócio para serem usadas pelos professores que estão disponíveis em: <http:// www.abagrp.org.br/media/pdf/abagrp-cartilha-agronegocio-escola-versao-professor.pdf $>$. Acesso em 29 jun. 2017.
} 
a posse da terra e também para conquistarem a política de Reforma Agrária. A esse paradigma que tem como ponto de partida as lutas de classe para explicar as disputas territoriais e suas conflituosidades na defesa de modelos de desenvolvimento que viabilizem a autonomia dos camponeses, Fernandes (2015) denominou de Paradigma da Questão Agrária (PQA).

Todavia, na região Extremo Sul da Bahia, as nossas pesquisas identificaram que os movimentos sociais estão utilizando uma nova estratégia de realizar a reforma agrária a qual estamos denominando de Reforma Agrária do Consenso, e definimola como uma forma específica de negociação para fazer reforma agrária, que acontece por meio de parceria e acordos realizados entre as empresas do agronegócio de eucalipto com os movimentos sociais do campo e o Estado. Tomamos como base os dados coletados em entrevista como demonstra a TABELA 1 a seguir, elaborada a partir da coleta na nossa pesquisa:

TABELA 1 - Diálogo dos sujeitos (Movimentos sociais, agronegócio e Estado)

\begin{tabular}{|c|c|}
\hline Sujeito da pesquisa & Sobre a negociação e a parceria para o consenso \\
\hline $\begin{array}{l}\text { Veracel - Entrevista realizada } \\
\text { na pesquisa de campo com o } \\
\text { gerente de sustentabilidade da } \\
\text { empresa. }\end{array}$ & $\begin{array}{l}\text { Nós fizemos um trabalho de separar o joio do trigo. Bom, } \\
\text { identificamos seis movimentos sociais, estabelecemos } \\
\text { uma linha de corte nesse horizonte temporal de julho de } \\
2011 \text {. Então negociamos com o governo do estado que nos } \\
\text { ajudou a mediar. A Veracel assumia naquele momento da } \\
\text { negociação de mesa, todas as áreas que estavam ocupadas } \\
\text { até julho de 2011. [...] Os movimentos sociais por sua } \\
\text { vez teriam que aceitar e aceitaram parte do acordo de } \\
\text { recuar das áreas ocupadas após julho de } 2011 \text {, ou seja, } \\
\text { sair espontaneamente daquelas áreas, e isso aconteceu } \\
\text { [...]. São seis movimentos: MST, o MLT, a FETAG, } \\
\text { APRUNVE, o MRC e o FTL. }\end{array}$ \\
\hline $\begin{array}{l}\text { MST - Márcio Matos, repre- } \\
\text { sentante da Direção Nacio- } \\
\text { nal do MST. Disponível em: } \\
<\text { http://www.vermelho.org.br/ } \\
\text { noticia/189167-8>. }\end{array}$ & $\begin{array}{l}1 \text { - "Chegamos a um novo paradigma de negociação } \\
\text { sobre passivos, diálogo que surgiu a partir de relações } \\
\text { conflituosas e se repetirá junto às demais empresas do } \\
\text { setor". (Grifos nosso). } \\
2 \text { - "Neste momento, encerram-se as diferenças entre o } \\
\text { MST e Fíbria, avançando em um modelo de agricultura } \\
\text { que possa permitir ao homem produzir sem prejudicar a } \\
\text { natureza". }\end{array}$ \\
\hline
\end{tabular}




\begin{tabular}{|c|c|}
\hline Sujeito da pesquisa & Sobre a negociação e a parceria para o consenso \\
\hline $\begin{array}{l}\text { Fetag/Ba - Dirigente da Fetag/ } \\
\text { Ba. } \\
\text { Dados adquiridos por meio } \\
\text { de correio eletrônico em } \\
16 / 11 / 2015 \text {. }\end{array}$ & $\begin{array}{l}\text { O processo de negociação entre Mov. Sociais, Empresas } \\
\text { e Governo, iniciou com a Fazenda Colatina, Mun. do } \\
\text { Prado, quando o MST e a Fíbria, mediados pelo Governo } \\
\text { do Estado, chegaram ao consenso (grifo nosso), pondo } \\
\text { fim ao conflito, daí, se estendeu, à outras propriedades da } \\
\text { Fíbria e Suzano, como também à várias áreas da Veracel, } \\
\text { tendo sempre, o governo do Estado, como interlocutor/ } \\
\text { mediador, envolvendo uma área no município de Itapebi } \\
\text { (Fazenda Candelária), ocupada pelo MRC e FTL, uma } \\
\text { área no município de Eunápolis (Fazenda São Caetano), } \\
\text { ocupada pela FETAG-BA e MLT, várias propriedades } \\
\text { ocupadas pelo MST e outras pela FETAG-BA. }\end{array}$ \\
\hline
\end{tabular}

Tabela construída pela autora a partir da análise dos dados coletados em 2015.

O trecho da entrevista da FETAG-BA traz uma síntese do que de fato aconteceu no processo de negociação entre os sujeitos e pressupõe o que Lukács (1968) descreveu em seu ensaio Marx e o problema da decadência ideológica, que retrata o período posterior às revoluções de 1848, quando os elementos ideológicos progressistas da burguesia, classe revolucionária daquela época, são trocados por elementos conservadores. Em nossa análise o mesmo conservadorismo acontece com os movimentos sociais analisados quando estabelecem as parcerias que estamos denominando da Reforma Agrária do Consenso.

A ideologia é um conceito polissêmico e enigmático da ciência social moderna. Segundo Michel Löwy (1987, p. 9-10), “ao longo dos últimos dois séculos se tornou objeto de uma acumulação incrível, até mesmo fabulosa, de ambiguidades, paradoxos, arbitrariedades, contrassensos e equívocos". O entendimento desse conceito como registro de pressões deformadoras não é recente visto que a sua origem remonta à Antiguidade, quando os gregos começaram a refletir sobre os problemas dos seres humanos de maneira mais concreta, sem se apegar aos mitos e às religiões, para que pudessem conhecer a origem do homem longe de falsas ilusões ou do escamoteamento da realidade. Nesse sentido, Platão, com o seu mito da caverna chamava a atenção dos seus discípulos sobre a possibilidade de ver sombras ao invés de seres reais, ou seja, enxergar a aparência e não a essência. Então, a preocupação com o conhecimento do real, e não somente do abstrato, passou a ser uma constante, principalmente para os filósofos que faziam especulações sobre a realidade. Os iluministas demonstravam um exacerbado otimismo na crença de que por meio do conhecimento todas as questões da humanidade poderiam ser resolvidas. E com o poder da persuasão, da argumentação racional e a socialização 
do conhecimento científico seria possível dar fim à ignorância, à superstição e o preconceito. (KONDER, 2002).

De acordo com essa percepção, a consciência era produto do meio e a realidade objetiva era compreendida pelas impressões sensoriais que por sua vez, eram reproduzidas pela ideologia, por meio da qual os homens chegavam mais próximo do real e se livravam dos subjetivismos. Dentre os socialistas, destaca-se inicialmente, Fourier (1970, p.27), que trata a ideologia como "catarata das mais espessas, que cega o espírito humano, deforma a sensibilidade, calunia as paixões e dificulta a compreensão dos homens entre si”. Entretanto, a tônica necessária seria acrescentar às concepções de ideologia a capacidade de reflexões sobre a crítica e a autocrítica mediante os conflitos advindos do conhecimento e das determinações históricas. Por isso, Kant e Hegel os filósofos do idealismo clássico, acrescentam a essa discussão a importância do sujeito na construção do seu conhecimento e responsável pela própria realidade do conhecimento adquirido ideologicamente. Os sujeitos poderão sair da condição de sujeitos sujeitados e se tornarem ativos, interferindo na realidade e no processo histórico. Assim, "começa a ser valorizada a construção subjetiva do conhecimento, e este deixaria de ser concebido apenas como um registro fiel e objetivo da realidade". (KONDER, 2002, p. 26).

Na concepção marxiana, foi sistematizada a compreensão do homem sobre o mundo existente (ontologia), sobre o próprio conhecimento (gnosiologia) e sobre as ações e valores humanos (axiologia); a sua concepção de ideologia está relacionada com o ajuste de contas que Marx fez com Hegel, principalmente, na concepção de Estado, em sua Crítica ao direito público hegeliano, na qual Hegel foi acusado por Marx de um formalismo inaceitável (MÉSZÁROS, 2011). Hegel atribui ao que idealizou como Estado ético, uma realidade histórica substantiva, destinada a subsumir a sociedade civil antagônica, sobre a qual ele é erigido como seu elemento constitutivo e de base material contínua. A temporalidade hegeliana de Estado é fundamentada em sua obra, pela noção do eternamente presente, que é, paradoxalmente, transfigurado na teleologia do Absoluto. Para Marx (1996), o Estado é o resultado da criação de homens alienados e está sujeito aos determinantes históricos. Se para Hegel o Estado é eterno, a-histórico e está acima da sociedade coletiva e ideal, para Marx é resultado do contexto histórico e moldado pela sociedade, e não o contrário. E a ideologia é responsável pela alienação ${ }^{4} \mathrm{ou}$ estranhamento por meio do qual o Estado se apresenta como um corpo estranho que submete a sociedade ao seu controle, sendo os indivíduos levados a acreditar numa ideia ilusória de um Estado racional que promove a paz e organiza a sociedade

\footnotetext{
4 Baseado em Marx, Mészáros (2011) afirma que a alienação se caracteriza pela extensão universal da vendabilidade; pela conversão dos seres humanos em coisas, de modo que apareçam como mercadorias.
} 
por meio da lei. Ou seja, diferente do que Hegel considerou como o Espírito do Mundo e a Razão Suprema, Marx enxergou como o responsável por legitimar as contradições entre as classes.

Para superar essa alienação seria necessário ir à raiz da mesma atacando a contraposição entre sujeito/objeto, por meio da compreensão histórica da realidade que reagiria contra as distorções ideológicas adquiridas nas relações de produção (trabalho) e fortaleceria a consciência crítica. Em A ideologia alemã, de Marx e Engels (2002), encontramos uma passagem importante do pensamento desses autores sobre a ideologia segundo a qual:

[...] os seres humanos elaboraram até agora falsas representações a respeito deles mesmos, do que são ou deveriam ser. [...] Libertemo-los das ficções do cérebro, das ideias, dos dogmas, das essências imaginadas sob cujo jugo se atrofiam. Rebelemo-nos contra o domínio das ideias. Ensinemo-los a trocar as fantasias por ideias que correspondem à essência do Homem. (MARX e ENGELS, 2002, p. 7)

Nesse sentido, estes pensadores apresentam a ideologia como uma visão distorcida da realidade cuja representação da mesma está condicionada ao idealismo subjetivo, no qual o Estado paira acima da sociedade. Concretamente, tais pressupostos são evidenciados na realidade pesquisada quando a classe dominante, por meio do agronegócio e do Estado, numa relação de exploração convence os explorados de que os mesmos estão sendo beneficiados pelas empresas de eucalipto. Entretanto, os exploradores são mais beneficiados, como se verifica na fala do representante da Veracel Celulose (Pesquisa de Campo) uma vez que a empresa fez investimentos na região Extremo Sul, pensando em seus próprios interesses.

A partir do momento que os acionistas se decidem por fazer a fábrica, fazer o investimento da fábrica, que foi um investimento de milhões de reais, a empresa entra numa segunda etapa, e aí para tornar a região mais atrativa, pra fixar pessoas que venham morar aqui para operar essa fábrica, fez uma série de investimentos. Como a região continha na época um déficit de cultura social muito grande, muito alta, a empresa teve que fazer muitos investimentos nessa área, e nos últimos dez anos a empresa investiu em cultura social. A empresa já fez parcerias com o Estado e com os municípios na melhoria de condições de saúde, construindo unidades e equipando unidades de saúde, foi responsável pela construção de uma série de unidades de saúde nos municípios, doação de materiais equipamentos, treinamento de pessoas. [...] Então, ela fez todo um trabalho de calçamento e pavimentação de ruas, que era de esgotos a céu aberto, fez toda a parte de drenagem pluvial de esgotamento sanitário e instalação de água potável nessa 
localidade, e fizemos também ao longo desse tempo vários anos investimentos na área de educação. (Trecho da entrevista com a Veracel, 2014).

Salientamos que a referida empresa é responsável por causar muitos danos ao meio ambiente e à saúde dos moradores nas suas redondezas. Tendo em vista os acordos legais estabelecidos de responsabilidade social, torna-se, pois, obrigatório que a mesma invista nas melhorias dos espaços públicos para que a comunidade prejudicada possa ter atendimento. Apesar disso, percebemos no relato que a preocupação da empresa é criar as condições para que os trabalhadores possam fixar na região explorada. Dessa forma, a Veracel alcança dois objetivos: manter trabalhadores de seu interesse na região; e construir ideologicamente um consenso generalizado de compromisso e responsabilidade social na sociedade civil, tornando presente o que Marx e Engels (2002) denominaram de falsas representações ou de uma visão distorcida da realidade. $\mathrm{O}$ trecho a seguir corrobora com esse pensamento:

[...] Isso não é filantropia, isso é negócio, interesse de negócio, filantropia não existe nessa questão. E se nós não tivéssemos motivos não estávamos envolvidos nesses conflitos e esses conflitos existem. São reais. Não podemos operar, não podemos estar na região e sendo competitivo, pelos custos inadequados, e sim, tendo imagem, reputação, e imagem que seja capaz de gerar confiança no mercado, de assumir isso sem que a gente esteja pendendo pra essa área, isso é um tipo de esforço, de relação. Isso é crucial, estratégia pro negócio, isso não é filantropia (Trecho da entrevista com a Veracel).

Como arauto do capital (neo)desenvolvimentista, o entrevistado deixa claro a importância do negócio e do mercado para a empresa na relação entre trabalhadores e capitalistas. Para tanto, utiliza-se do mecanismo da cooptação por meio de pequenas benesses, de forma que a sociedade acredite que a empresa está sendo solidária e filantrópica. Indubitavelmente, a ideologia capitalista se manifesta nesse contexto. Além de utilizar a força da razão material e um arsenal políticoideológico à sua disposição na sociedade civil, o agronegócio, enquanto classe dominante, exerce seu poder ideológico na regional Extremo Sul, beneficiando-se da mistificação, por meio da qual as pessoas que sofrem as consequências da ordem estabelecida são induzidas a legitimar na forma de consenso, os valores e as políticas que são contrários aos seus próprios interesses. Contudo, o fazem, acreditando que estão agindo de maneira correta para o seu bem-estar, pois o referido consenso é construído por meio de instituições que exercem o poder hegemônico na consciência de classe. No caso do nosso objeto de estudo, a mediação para a construção do consenso entre os movimentos sociais e o agronegócio foi realizada pela Escola 
Superior de Agronomia (ESALQ), da Universidade de São Paulo (USP) e pelo governo do estado da Bahia.

\section{O MST e a reforma agrária do consenso}

De acordo com os estudos realizados por Stédile (2013) e Bogo (2009), podemos concluir que o MST, em sua origem, destacava-se como movimento social do campo que visava, principalmente, à luta pela terra e à valorização do campesinato brasileiro. Entretanto, na atualidade, nas leituras de Santos (2013) e Hilsembeck Filho (2013), bem como na nossa pesquisa de campo, ficou evidenciado que o MST passou por intensas transformações nas últimas duas décadas, sendo que há uma notável distância qualitativa entre as suas características fundantes - que marcaram as décadas de 1980 e 1990 - em relação às expressas nos anos posteriores à chegada do governo Lula ao Planalto, em 2003.

$\mathrm{Na}$ atualidade, o MST é o movimento de maior expressividade no campo brasileiro. Ele preconiza teoricamente uma reforma agrária contrária à do livre desenvolvimento do capitalismo na agropecuária, bem como, a concentração de terras por parte de grandes conglomerados empresariais (SANTOS, 2013). Nesse movimento social, nas palavras de um de seus dirigentes nacionais, João Pedro Stédile, entende-se que a disputa pela terra deve se transformar em disputa pelo território, significando terra, biodiversidade, florestas, água, recursos naturais, e pelas concepções produtivas e culturais, principalmente no que tange à qualidade e à saúde dos alimentos (REPÓRTER BRASIL, 2013). A esse paradigma de reforma agrária, o MST denomina de Reforma Agrária Popular. Outro intelectual do MST, Ademar Bogo (2009), entende que essa reforma agrária defendida pelo Movimento tem um caráter de ir aos poucos, conquistando a revolução socialista:

Podemos dizer que, por duas razões, a reforma agrária está ligada à revolução. A primeira por ela estar no campo das "reformas" em que obrigatoriamente deve impulsionar a revolução para a frente por meio da luta pelas necessidades imediatas dos Trabalhadores Sem Terra e da sociedade. A segunda razão, por ela estar vinculada a essa concepção antecipada da sociedade socialista que pretendemos construir, em que a propriedade privada sofrerá mudanças profundas na forma de sua existência”. (MOREIRA, 2016, p. 90)

A essência do significado de revolução é diferente do significado de reforma, pois enquanto na primeira subtende-se que deve haver uma transformação radical, na segunda, como o próprio nome indica, será feita apenas uma mudança gradual. $\mathrm{O}$ 
MST almeja chegar à revolução iniciando pela reforma, que nesse caso a proposta é de que seja feita com a intervenção da manipulação superestrutural (Estado), a qual tem se demonstrado estar a serviço da classe dominante com a participação dos apologetas da ordem estabelecida. Depreende-se desse contexto a reforma como um revolucionismo esvaziado, que dá uma aparência ilusória de revolução. Entretanto, para que a revolução socialista aconteça ipso facto faz-se necessária uma mudança no quadro global com uma teoria que oriente as metas dos trabalhadores e os livrem da imediaticidade.

Nesse sentido, tanto o MST quanto os demais movimentos sociais pesquisados propõem reforma gradual, até alcançar a revolução, tomando o caminho da socialdemocracia. Para Mészáros (2011), na socialdemocracia podese permitir atuar dentro dos limites da imediaticidade, com o pragmatismo e a engenharia social gradual, buscando mudanças particulares desprovidas de um quadro estratégico de referência, visto que as estratégias socialistas desafiam o imediatismo, desde os complexos mistificadores/ideológicos e materiais institucionais da formação estatal estabelecida até a internalização das inevitáveis pressões do capital na classe trabalhadora. Nesse sentido, a ideologia transmitida pelos movimentos sociais contribuirá para a manutenção do sistema capitalista, e não para a sua superação.

Diferentemente do que se previa nos objetivos do $3^{\circ}$ Congresso Nacional do MST, onde encontramos uma proposição ao sistema socialista por meio do lema Difundir os valores humanistas e socialistas nas relações sociais (MST, 1995), no VI Congresso Nacional, o MST (2014) deixa clara a sua mudança de foco quando afirma que:

O Programa de Reforma Agrária Popular não é um programa socialista (grifo nosso) - embora os objetivos estratégicos da nossa luta sejam os de construir uma sociedade com formas superiores de socialização da produção, dos bens da natureza e um estágio das relações sociais na sociedade brasileira. [...]. (MST, 2014, p. 49)

Assim, o tipo de reforma agrária popular defendida pelo MST, com a participação de movimentos sociais do campo e da cidade, incidiria diretamente não apenas na concentração fundiária, uma vez que no mesmo programa agrário do VI Congresso Nacional do MST, ao defender o uso da terra estabelecendo o tamanho máximo da propriedade, o Movimento, contraditoriamente, não deixa de defender a propriedade privada da terra. Porém, de uma forma mais socializada, com a mediação das forças populares. Entretanto, cabe perguntar: 1) Qual o paradigma social que essas forças populares estarão defendendo, uma vez que o Movimento 
demonstra que os seus dirigentes idealizam up to date alcançar a superação do capitalismo defendendo uma proposta (neo)desenvolvimentista, voltada para as mudanças graduais? 2) É possível vencer o capitalismo sem realizar uma mudança estrutural radical?

Em primeiro lugar, se o MST em um determinado contexto histórico, a priori, defende teoricamente a luta pelo socialismo com mudanças graduais, e a posteriori, suas práticas se voltam para o conservadorismo da sociedade de classes, com a participação nas esferas estatais, observa-se a existência de uma falsa consciência social ou uma práxis míope, pois percebemos nesse caso um contrassenso, uma vez que a função do Estado é exatamente legitimar a sociedade de classes e justificar as desigualdades sociais. Assim, ajusta-se ao ideário da socialdemocracia, cuja proposição de mudanças graduais não é sequer gradual, mas sim, conciliatória, havendo então, uma decadência ideológica.

De acordo com Mészáros (2011), a socialdemocracia apresenta um ponto ideológico cego e suas limitações pela inserção na política parlamentarista a paralisa e transforma em um exercício manipulador de relações públicas com o objetivo de ser eleito ou permanecer no cargo. Não obstante, a classe revolucionária passa a ser expropriada do seu conteúdo revolucionário, sendo valorizada apenas em momentos pré-eleitorais e depois é transformada no que foi preconizado pelo socialismo evolucionário de Bernstein (1964, p. 218): "de setor ativo da consciência de classe do proletariado, para a massa amorfa de um eleitorado [...] a qual ainda se acha vitoriosa e celebra a ascensão da socialdemocracia", tal como acontece com os movimentos sociais na atualidade, cuja prática tem sido deixar de lutar numa perspectiva revolucionária para se associar aos ditames do Estado (neo) desenvolvimentista.

Ricci (2010) denominou o período (neo)desenvolvimentista do governo brasileiro, assumido inicialmente por Luiz Inácio Lula da Silva, de Lulismo. Para esse autor:

O lulismo seria caudatário do "conservadorismo popular". Identificado como um governo de modernização conservadora. Dialoga abertamente com organizações, sindicatos, mas os incorpora ao Estado a partir de políticas específicas, fundadas em convênios e parcerias, algo que se aproxima da tutela, já que não incorpora efetivamente esses atores sociais na formulação de políticas públicas, pois estas, geralmente são formuladas pelos técnicos. Lula é apenas um dos personagens do lulismo. (RICCI, 2010, p. 34)

Em segundo lugar, essa proposição do diálogo foi o que ipso facto aconteceu com o Projeto Assentamentos Sustentáveis na regional Extremo Sul da Bahia, 
implementado como estratégia de negociação para a Reforma Agrária do Consenso. O referido projeto foi elaborado pela ESALQ/USP, cujo foco principal é desenvolver modelos de ocupação, produção e preservação das Agro Florestas locais, enfatizando a preocupação com a manutenção da biodiversidade regional. De acordo com informações do governo da Bahia, por meio da SERIN, trata-se de uma parceria inédita envolvendo diferentes setores da sociedade, tais como: a universidade; as três esferas do governo (municipal, estadual e federal); empresas e movimentos sociais ${ }^{5}$. De acordo com os sujeitos pesquisados o Projeto Assentamentos Sustentáveis contempla a distribuição de terras para a reforma agrária e a implementação de políticas públicas nas áreas atendidas, de forma que os assentados tenham melhoria na qualidade de vida e possam produzir com base na agroecologia. Só nas áreas da Veracel Celulose, esse projeto contempla 19 ocupações, de sete movimentos sociais, totalizando cerca de 10 mil hectares. Segundo o coordenador do projeto, pesquisador da ESALQ/USP,

A Veracel está abrindo mão dessas terras e cedendo-as ao Incra, para serem desapropriadas e incorporadas ao programa de Reforma Agrária. A empresa está propondo uma parceria com a sociedade, contribuindo para que a produção rural seja agroecológica, livre de agrotóxicos e viável financeiramente. E isso pode significar uma revolução nessa região. (ASCON, 2013, n. p.)

De acordo com dados coletados por meio de recortes de jornais ${ }^{6}$, o Instituto Nacional de Colonização e Reforma Agrária (INCRA) compra as terras para assentar as famílias. Como parte do acordo celebrado, no final de 2011, a Fíbria S.A. anunciou a parceria de um projeto de assentamento de 10 mil hectares na regional pesquisada, destinado a alocar mil e trezentas famílias, no assentamento Jaci Rocha, município do Prado (BA), tendo por parceiros o INCRA, o governo da Bahia e o MST.

O Governo da Bahia, o Movimento dos Trabalhadores Sem-Terra (MST), a Escola Superior de Agricultura Luiz de Queiroz da Universidade de São Paulo (Esalq/USP) e a Fibria, parceiros no projeto 'Assentamentos Sustentáveis com Agroflorestas e Biodiversidade" (...) visa dar às famílias do MST assentadas na região e a algumas comunidades de municípios do extremo sul baiano acesso à formação técnica, educacional e organizacional para a produção de alimentos

\footnotetext{
5 No site da Fíbria há uma matéria sobre o Projeto Assentamentos Sustentáveis. Disponível em: <http:// www.fibria.com.br/midia/releases/entrega-da-fazenda-colatina-para-familias-assentadas-pelo-incra-nabahia-consolida-projeto-assentamentos-sustentaveis-com-agroflorestas-e-biodiversidade/>. Acesso em 29 jun. 2017.

6 Os dados podem ser encontrados em Santos (2016).
} 
com base nos princípios agroflorestais e agroecológicos e na organização social. (FIBRIA, 2012, p. 56)

A partir desse momento, lideranças do MST começaram a frequentar reuniões estratégicas da Fíbria, até mesmo em outros países, para discutir os rumos dessa parceria ${ }^{7}$. De acordo com a reportagem MST e Fíbria: aliança inédita encerra conflito no campo (VERMELHO, 2012, n.p.), para o pesquisador da ESALQ/ USP, Paulo Kageyama, um dos elaboradores do projeto, "muda-se a relação entre capital e trabalho". Na opinião do presidente do conselho de administração da Fíbria, José Penido, essa parceria "é um marco no convívio do agronegócio com a agricultura familiar" e "a estratégia é superar antagonismos e encarar os problemas historicamente agudos no sul da Bahia". Já na opinião do dirigente nacional do MST, Márcio Matos, a referida parceria aponta para "um novo paradigma de negociação sobre passivos, diálogo que surgiu a partir de relações conflituosas e se repetirá junto às demais empresas do setor". Observamos assim uma confluência no discurso e o consenso dos sujeitos em torno dos interesses do agronegócio que representa o grande capital no campo brasileiro.

O acordo originado com a mediação do Estado nesse contexto trata principalmente do convencimento dos trabalhadores para deixar documentado que a partir do mês de junho de 2011, não se ocuparia mais terra do agronegócio na região, passando a ideia de que poderia ser um bom negócio na medida em que as empresas capitalistas do campo também não pediriam reintegração de posse das terras que foram ocupadas até aquela data. Assim, parece originar daí uma nova estratégia para a política de reforma agrária, a partir do diálogo e consenso entre as classes antagônicas. Estamos designando-o de Reforma Agrária do Consenso e coadunamos com Ariovaldo Umbelino de Oliveira (2010), quando afirma que a política de reforma agrária do governo do PT está marcada por dois princípios:

Não fazê-la nas áreas de domínio do agronegócio e fazê-la apenas nas áreas onde ela possa "ajudar" o agronegócio. Ou seja, a reforma agrária está definitivamente acoplada à expansão do agronegócio no Brasil. É como se estivesse diante de uma velha desculpa: o governo [...] finge que faz a reforma agrária e divulga números maquiados na expectativa de que a sociedade possa também fingir acreditar (OLIVEIRA, 2010, p. 90).

No Projeto Assentamentos Sustentáveis em parceria com os movimentos sociais do campo no Extremo Sul da Bahia, chamado pela Fíbria (2012) de projeto popular de país com sustentabilidade ambiental e social, a referida empresa destinou

7 Sobre os convênios públicos e o desenvolvimento da agroindústria no MST ver Quadros (2013). 
em 2011 investimentos em áreas de assentamentos, no montante de mais de 20 milhões de reais, com a decisão de se tornarem assentamentos exemplares de um projeto de agroecologia e sistemas agroflorestais para o Brasil.

\section{Conclusão}

O Estado brasileiro, não diferente do que Marx (1996) preconizou, está composto de um staff que responde aos interesses da classe dominante no poder, contribuindo para a manutenção do conservadorismo no campo brasileiro. No tocante à reforma agrária, as questões pontuadas nesse texto demonstram que a tônica governamental tem sido a implementação de uma política agrícola de subordinação dos camponeses aos grandes empresários de commoditties no campo, pautada no paradigma do capitalismo agrário. Assim, observa-se que a reforma agrária daí depreendida, idealizada nos gabinetes do agronegócio e da burocracia estatal, pelos apologetas do capital, é um instrumento de subordinação de uma classe à outra, e vem sendo utilizada como forma de manutenção do controle e do desenvolvimento desigual no campo brasileiro.

$\mathrm{O}$ ineditismo da aliança entre o agronegócio e os movimentos sociais deve-se ao diálogo estabelecido, que resultou na realização de acordos por meio dos quais as empresas do agronegócio de eucalipto têm contribuído com os movimentos sociais do campo no Extremo Sul da Bahia, com financiamentos para a implementação de projetos pautados na agroecologia, e ainda para a construção de agroindústrias e de espaços educativos em assentamentos. Todavia, a contrapartida negociada é que os movimentos sociais do campo não deverão ocupar as áreas destas empresas de eucalipto, surgindo assim, um novo jeito de fazer reforma agrária, fundamentado no consenso realizado com a mediação do Estado (Neo)desenvolvimentista, o qual tem a tarefa de regulamentar essa relação antagônica entre capital e trabalho, intermediando o diálogo entre o campesinato e o agronegócio, mas subordinando os camponeses cada vez mais às demandas das grandes empresas e do capital financeiro. Segundo os sujeitos parceiros, as vantagens obtidas nessa relação são: a) O agronegócio não terá suas terras ocupadas pelos movimentos sociais que estabeleceram a parceria naquele espaço; b) O Estado terá conseguido resolver as situações de conflito na região, implementando um novo modelo de reforma agrária nas áreas dos movimentos sociais e c) Os movimentos sociais parceiros receberão recursos para implementação de projetos em suas áreas. Essa nova estratégia para realização da reforma agrária tem como objetivo a conquista da paz social no campo, a qual, segundo os empresários do agronegócio, até o momento tem sido alcançada. 


\section{The MST AND LAND REFORM OF CONSENSUS}

ABSTRACT: This text puts forth the results of research undertaken in the Far South of Bahia, which analyzed the partnerships, agreements and dialogue established between social movements of the country, mainly the Landless Movement, the State and agribusiness companies. We used exploratory qualitative methodology to analyze data collected through review of documentation and semi-structured interviews. The results show that in the Brazilian region studied, a new agrarian reform is taking place, which we're styling Consensus Agrarian Reform.

KEYWORDS: Agribusiness. Ideology. Rural Social Movements. Consensus Agrarian Reform.

\section{REFERÊNCIAS}

ABRAMOVAY, Ricardo. Paradigmas do capitalismo agrário em questão. São Paulo: Edusp, 2007.

ASCOM. Prefeitura de Porto Seguro. Assentamentos sustentáveis: projeto em Porto Seguro poderá ser modelo para o Brasil. A Gazeta da Bahia. 29 de abril de 2013.Disponível em: http://www.agazetabahia.com/noticias/geral/3123/assentamentos-sustentaveis-projeto-emporto-seguro-podera-ser-modelo-para-o-brasil-29-04-2013/ Acesso em: 05 jan. 2016.

BERNSTEIN, Basil. O socialismo evolucionário. Rio de Janeiro: Zahar editores. Tradução de Manuel Teles, 1964.

BOGO, Ademar. O MST e a cultura. São Paulo: MST, 2009.

BRASIL. Senado Federal. Constituição Federal de 1988.

. Lei 4.504/64. Dispõe sobre o Estatuto da Terra, e dá outras providências. Diário Oficial de 30.11.1964.

FARIAS, L. F. C. Agronegócio e luta de classes: diferentes formas de subordinação do trabalho o capital no complexo agroindustrial citrícola paulista. Dissertação de Mestrado. UNICAMP. 2013.

FERNANDES, B. M. Reforma agrária no Brasil, para além de um projeto: uma luta permanente. In: MIDITIERO JR, M. A.; GARCIA, M. F.; VIANA, P. C. G (Org.). A questão agrária no século XXI: escalas, dinâmicas e conflitos territoriais. 1. ed. São Paulo: Outras Expressões, 2015. 
FÍBRIA. Relatório de sustentabilidade. Fíbria Celulose S.A. 2012. Disponível em: <http:// www.fibria.com.br/relatorio2013/shared/relatorio-de-2012-firmes-no-rumo-7abr2014.pdf.>. Acesso em 23 out. 2015.

FOURRIER, C. Le Nouveau Industriel et sociétaire. In: . Oeuvres completes, vol. VI. Londres, Anthropos, 1970.

GIL, Antônio Carlos. Métodos e técnicas de pesquisa social. 5. ed. São Paulo: Atlas, 2002. HILSENBECK FILHO, Alexander Maximilian. O MST no fio da navalha - dilemas, desafios e potencialidades da luta de classes. Tese de doutorado. Universidade Estadual de Campinas. Instituto de Filosofia e Ciências Humanas. 2013.

KONDER, Leandro. A questão da ideologia. São Paulo: Companhia das Letras, 2002.

KOSIK, Karel. Dialética do concreto. 6. ed. Paz e Terra: Paz e Terra, 1997.

LÖWY, Michel. As aventuras de Karl Marx contra o Barão de Münchhausen. Trad. De Juarez Guimarães e Suzanne Felício. São Paulo, Buscavida, 1987.

LUKÁCS, George. Marxismo e teoria da literatura. Rio de Janeiro, Civilização Brasileira. 1968.

MARX, Karl e FRIEDRICH, Engels. A ideologia alemã. Tradução José Carlos Bruni e Marco Aurélio Nogueira. São Paulo: Hucitec. 2002.

MARX, Karl. A assim chamada acumulação primitiva. In: MARX, K. O Capital: Crítica da economia política, livro I, tomo II. Tradução Régis Barbosa e Flávio R. Kothe. São Paulo: Nova Cultural, 1996. pp. 339- 394. Coleção Os Economistas.

MÉSZÁROS, Ístvan. Para além do capital. Tradução Sérgio Lessa. São Paulo: Boitempo. 2011.

MOREIRA, Leonardo Silva. O MST e a reforma agrária. Jornal Passa Palavra. 23 set. 2012. Disponível em: <http://www.passapalavra.info/2012/09/64686>. Acesso em: 22 fev. 2016.

MST. Princípios da Educação no MST. Caderno de Educação, n. 8, Porto Alegre. 1995.

. Cartilha do Programa Agrário do MST. VI Congresso Nacional do MST. São Paulo. 2014.

OLIVEIRA, Ariovaldo Umbelino de. O que significa agronegócio? 2010. Disponível em: $<$ http://www.seea.org.br/artigojoseadilson2.php>. Acesso em: 13 nov. 2015.

QUADROS, Vasconcelos. Com agricultura familiar, MST adere a estratégias capitalistas. IG São Paulo. Publicado em 14 de outubro de 2013. Disponível em: <http://ultimosegundo. 
ig.com.br/brasil/2013-10-14/com-agricultura-familiar-mst-adere-a-estrategias-capitalistas . html>. Acesso em: 29 jun. 2017.

REPÓRTER BRASIL. Reportagem, 03 de julho de 2013. Disponível em: $<$ http:// reporterbrasil.org.br/2013/07/para-joao-pedro-stedile-tempo-da-reforma-classica-passou/>. Acesso em: 29 jun. 2017.

RICCI, Rudá. Lulismo: da era dos movimentos sociais à ascensão da nova classe média. Brasília: Fundação Astrojildo Pereira. 2010.

SANTOS, Arlete Ramos dos. Aliança (neo)desenvolvimentista e decadência ideológica no campo: os movimentos sociais e a reforma agrária do consenso. Editora CRV: Curitiba, 2016.

. Ocupar, resistir e produzir também na educação. O MST e a burocracia estatal: negação e consenso - 2013. Tese de Doutorado, Faculdade de Educação, Universidade Federal de Minas Gerais. 390f. 2013.

STÉDILE, João Pedro. A Questão Agrária no Brasil. vol. 7. São Paulo: Expressão Popular, 2013.

THOMAZ JR. A classe trabalhadora no Brasil e os limites da teoria - qual o lugar do campesinato e do proletariado? In: FERNANDES, B. M. (org.) Campesinato e agronegócio na América Latina: a questão agrária atual, São Paulo: Expressão Popular, 2008.

VERMELHO. MST e Fíbria: aliança inédita encerra conflito no campo. Portal Vermelho. 23 de julho de 2012. Disponível em: <http://www.vermelho.org.br/noticia.php?id noticia $=189167 \&$ id_secao $=8>$. Acesso em: 22 out. 2015 .

Recebido em 27/12/2016.

Aprovado em 03/07/2017. 